\title{
CLINICAL AND ELECTROMYOGRAPHIC STUDIES OF "SPINAL REFLEXES" IN PREMATURE AND FULL-TERM INFANTS
}

\author{
BY \\ I. FÉNYES, Ch. GERGELY, and Sz. TÓTH \\ From the Institute of Neurosurgery and the Schöpf-Merei Hospital, Budapest
}

\begin{abstract}
After the fundamental animal experiments of Sherrington (1910) and Graham Brown (1913, 1916) the occurrence of so-called "reflexes of medullary automatism" or simply "spinal reflexes" in human beings has been discussed by many authors (Marie and Foix, 1912; Walshe, 1914; Böhme, 1916, 1919; Foerster, 1936; and others). There seems to be general agreement that these reflexes occur in adults in pathological conditions exclusively. But there is a great difference between the possibility of eliciting the flexion and the extension reflexes, since the flexion reflex can be elicited in cases of a completely divided spine in human beings relatively early after the injury, whereas the extension reflex appears only years after verified medullary division, and only recently have proper measures been taken to ensure the survival of such patients for sufficient periods of time (Kuhn and Macht, 1949; Kuhn, 1950).
\end{abstract}

The situation is, however, not quite the same with less developed nervous systems, such as those of premature and full-term infants, since some authors claim that there are spinal reflexes in infants even under normal conditions (Stengel, 1945; AndréThomas and Saint-Anne Dargassies, 1952; Peiper, 1956), whereas, according to Brudziński (1908), they are present only in pathological states. As the methods employed for studying these reflexes are different, it is very difficult to compare the results obtained by the different authors. We have, therefore, endeavoured to find a method by which such reflexes may be regularly elicited, and consider that premature infants are particularly suitable for such studies as in them the central nervous system is the least developed. First of all, we wanted to know whether there existed a method by which these reflexes could be elicited as a rule in the very early phase of nervous development, and if so, where was the limit beyond which these reflexes disappear in the course of ontogenetical development or become, at least, latent clinically, as has been demonstrated, e.g., by Wegener (1927), for the crossed adductor reflex.

The electromyographic studies supplementing these investigations facilitated a more detailed analysis of the phenomena observed, and also made clinically undetectable phenomena demonstrable.

\section{Methods}

We wish to emphasize that the results obtained in reflex studies, especially for the extremely unsteady nervous system of infants, depend to a great extent not only on the method employed but also on its proper evaluation. Moreover, it may be difficult to differentiate between the expected reactions and the eventually very similar spontaneous motor activity. For this reason, such reactions can only be relied on if they can be elicited repeatedly. Also the position of the limb in question has a considerable influence. Furthermore, pain reactions, e.g., crying, may cause general muscular spasms, which check the elicitability of the reflexes.

To elicit spinal reflexes we employed four methods, three of which have been described in the literature. They are (1) passive flexion or extension of the leg; (2) light touch applied on proximal areas of the leg, inguinal region, genitals, and perineum; (3) strong pinprick on the sole. All these stimuli may elicit essentially either a flexion or an extension type of reflex, these being the two principal patterns of spinal reflexes. Thus, passive flexion or extension will elicit contralaterally either an identical or an opposite motor effect, i.e., flexion or extension, light touch, homolateral extension, pinprick, homolateral flexion and contralateral extension.

The fourth technique of eliciting the crossed extension reflex has been mentioned by Fulton (1949) in connexion with animal experiments and we have applied it to humans. It involves strong pressure exerted on that point of the femoral nerve where it leaves the inguinal canal. The reflex 
response to be expected is an extension of the contralateral, less often of the homolateral, leg. It should be pointed out that the reflex response has various grades, because the extension may be full or partial, as determined from the angle of the knee joint, rectilinear, obtuse, right, and sharp angle, respectively. As the reflex itself is a variant of the crossed extension reflex, it seems reasonable to designate it in clinical practice the "crossed inguinal extension reflex".

All of the following four techniques were employed in each case studied.

The electromyograms were recorded by Kaiser's eightchannel E.E.G. apparatus. With the eliciting of the reflex, i.e., pressure on the femoral nerve, the time signal ceases during the time of stimulation and reappears afterwards. The recording of the stimulation was not automatic, as it was not the purpose cf the present investigation to study time-relations of the reflex responses. Thus, the time signal was recorded in response to a verbal signal given from the examiner. Hence, some shifting on the curve could not be avoided without disturbing the observations made on the muscle contraction or the potential changes. The electrcmyc grams seldcm show complete quietness before and after the muscle contractions, which can be explained by the nature of our material. The electrodes were co-axial and superficial needles with leads applied to the extensor quadriceps femoris, the hamstring muscles, the tibialis anterior, and the gastrocnemius.

\section{Results}

Except for a few adults, the test subjects were practically normal premature and full-term infants. The premature infants were examined shortly after delivery, the full-term ones from 1 or 2 days of age until 1 year.

The total number of premature infants examined was 90 , of whom 71 were tested within 24 to 48 hours of delivery and 19 under 1 year of age. Eighty-two full-term infants were studied, 34 as neonates and 48 in the course of the first year of life.

The results may be outlined as follows. Techniques 1,2 , and 3 elicited spinal reflexes, notably the crossed extension reflex, only occasionally and even then in the form of a mild extension only. In contrast technique 4 was remarkably efficient and reliable, because in the majority of both premature and fullterm infants this reflex could be elicited promptly and repeatedly in the form of a marked extension. There was still, however, a difference between the two groups. Premature infants almost invariably responded with a full extension, whereas full-term ones showed this grade of response only in about onequarter of the cases, the rest showing some of the lower grades, most often three-quarters extension.

Studies on infants under 1 year of age revealed that in the course of the first jear of life the reflex ceased to be obtainable in a clinically manifest form except in exceptional cases. However, there was a difference between the two categories, in that the reflex disappeared soon after the newborn age in the full-term group, whereas it could be elicited in premature infants until about 1 year of age usually in some of the lower grade responses.

To sum up, with our technique the crossed inguinal extension reflex can be elicited in most fullterm and premature newborn infants in the form of full extension, in the former in a lower grade response, in premature infants under 1 year of age in a lower grade response, and in full-term infants under 1 year of age only in exceptional cases.

In normal adults we could not elicit the reflex in a clinically manifest form with our technique.

The clinical appearance of the crossed inguinal extension reflex showed that in most cases the full extension of the leg in the hip and the knee was accompanied by dorsal flexion of the foot and toes, chiefly of the big toe. In the electromyographic curve this was shown by the synchronous electrical activity of both extensors and flexors, in the thigh by the quadriceps femoris and the hamstring muscles, below the knee by the tibialis anterior and the gastrocnemius. Thus, antagonistic muscles contracted at the same time, one group of muscles was sometimes more active than the other, but not $\stackrel{\mathbb{Q}}{\overrightarrow{0}}$ always the same group. So when the crossed inguinal $\bar{D} \frac{\mathbb{D}}{O}$ extension reflex is elicited in one case the extensors 8 of the knee and the plantar flexors of the foot are activated, and in another the flexors of the knee and the dorsal flexors of the foot. With the elicitation of the flexion reflex it was vice versa.

\section{Discussion}

Our investigations have shown that reflexes of the so-called "medullary automatism", i.e., the flexion and extension reflexes, in particular the crossed extension reflex, which occur in adults in pathological conditions only can be elicited in infants by a proper technique under normal conditions, but only in a very low grade of nervous development. In our premature cases the upper weight limit was $2,200 \mathrm{~g}$., the lower $600 \mathrm{~g}$., but no substantial difference could be found between the different weight groups in the ability to elicit the reflex. However, the reflex undergoes an alteration during ontogenetical development, since later it appears not in the form of full extension but in the form of diminished extension. Thus, in newborn premature infants the crossed inguinal extension reflex can be elicited in the form of full extension, but later the reflex gradually disappears. Full-term newborn infants, whose nervous development is higher, show the 


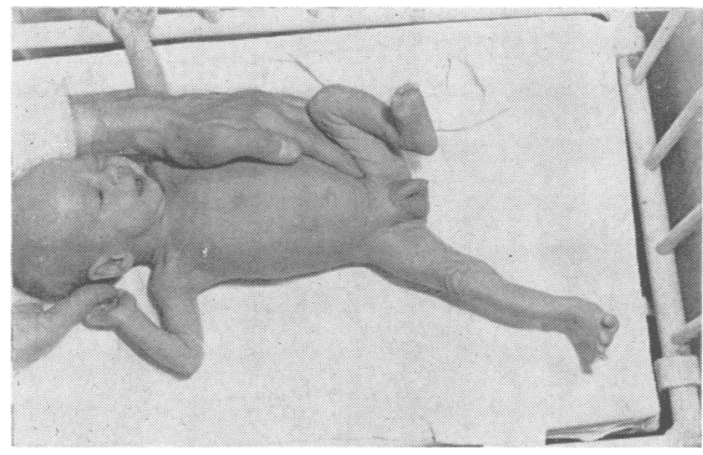

Fig. 1.-Elicitation of the crossed inguinal extension reflex from left to right in normal premature infant.

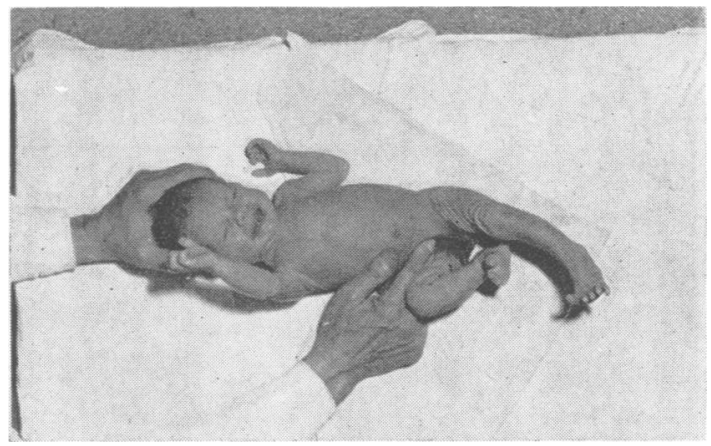

FIG. 2.-Elicitation of the crossed inguinal extension reflex from right to left in a normal premature infant.
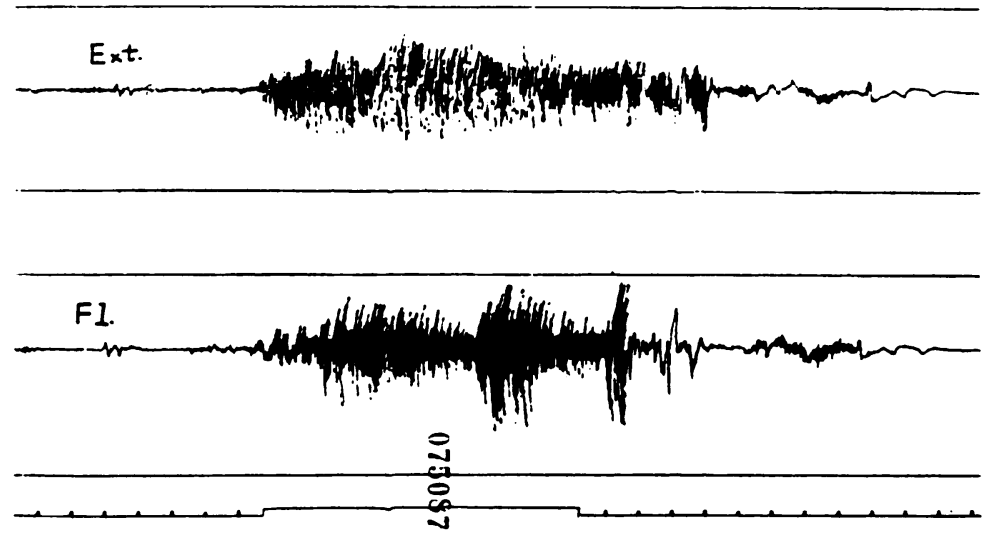

FIG. 3.-Electromyogram of the crossed inguinal extension reflex of a normal premature infant. Ext.=extensor; Fl. = flexor.

reflex, but only in about one-quarter of the cases in the full form, the majority showing lower grade responses. Since it takes several weeks for the premature infant to reach the degree of ontogenetical development comparable to that of the full-term infant the gradual disappearance of the reflex in the form of lower grade responses will be noticeable in the course of the first year of life.

Our results do not compare readily with those published by other authors, because our technique has not been applied to human beings before. André-Thomas and Saint-Anne Dargassies (1952) elicit the crossed extension reflex ("allongement croisé") by pinprick in full-term infants and describe flexion of the leg as the first phase, followed by extension and adduction. According to them, the reflex is already changing during the first postnatal month and later it is restricted to the flexion phase. Although we could elicit the reflex in question by this method only exceptionally, the data for the disappearance of the reflex reported by them are essentially the same as ours.

The extensive neurological studies on premature infants carried out by Saint-Anne Dargassies (1955) include the crossed extension reflex. According to her, in the period corresponding to the fifth or sixth months of pregnancy the reflex can be elicited in a rudimentary form, or not at all, becoming readily excitable only during the seventh month of pregnancy. 

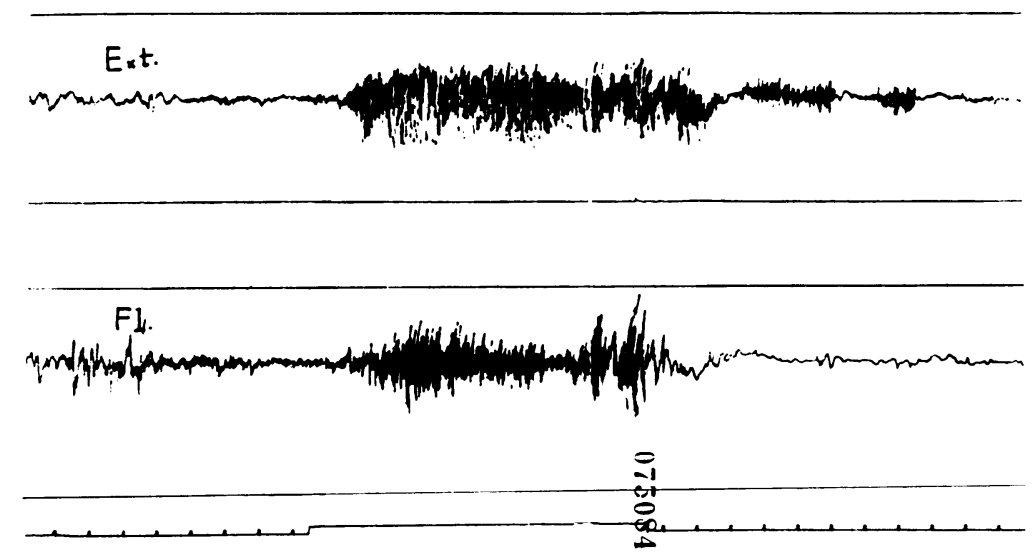

FIG. 4.-Electromyogram of the homolateral inguinal extension reflex of a normal premature infant.

\section{$\mathrm{I}_{300 \mu} \mathrm{V}$}

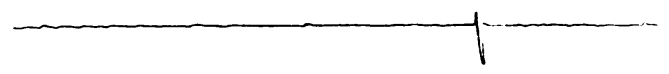

Fl.

Fl.
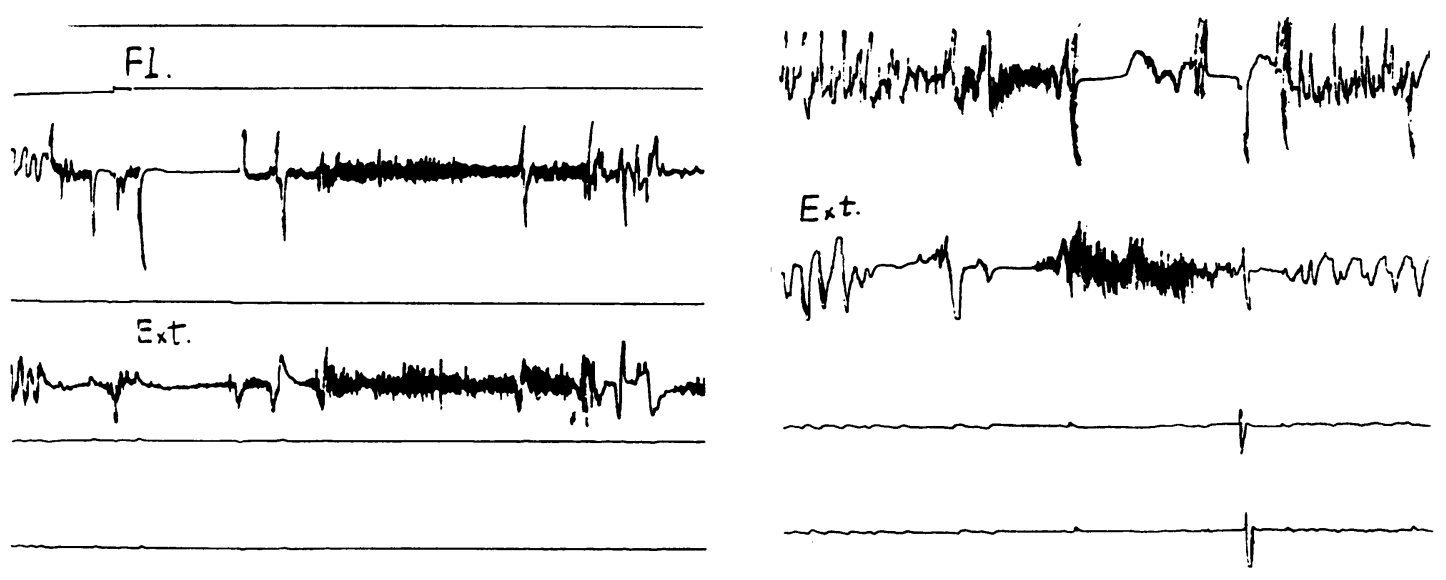

FIG. 5.-Electromyogram of the crossed inguinal extension reflex of a normal premature infant (another case).

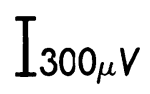

FIG. 6.-Electromyogram of the crossed inguinal extension reflex of a normal premature infant (another case). First: contraction of the flexor, when it ceased; contraction of the extensor.

Brudziński (1908) observed both the crossed extension and flexion reflexes in children exclusively in pathological conditions, eliciting them by a strong passive flexion of the contralateral leg. In contrast, Peiper (1956) claims that the crossed flexion reflex

can be elicited in every normal newborn and it disappears during the seventh month of life (Stengel, 1945). We are unable to confirm these data and share, therefore, the view put forward by Brudziński (1908) because we did not find that we could elicit 

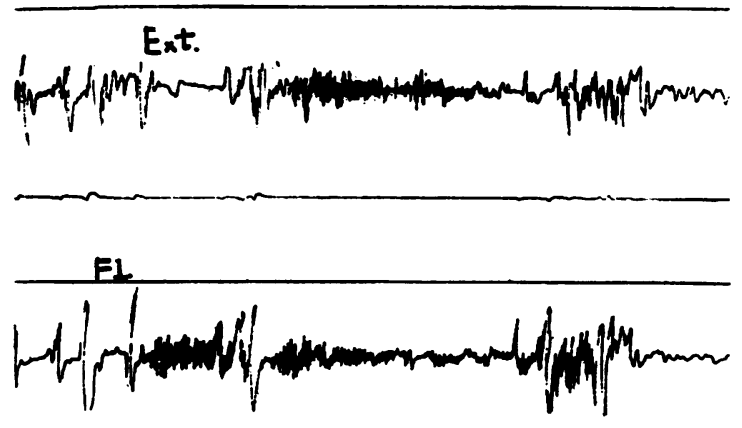

FIG. 7.-Electromyogram of the crossed inguinal extension reflex of a normal premature infant (another case). First: contraction of the flexor, which does not cease when the contraction of the extensor is beginning.

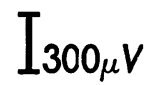

these reflexes in normal infants by strong passive flexion.

Although the technique of eliciting the "Leistenbeugereflex" (inguinal flexion reflex) described by Peiper (1941) is similar to ours, it is different in nature, both as regards the response and the significance. Here, too, strong pressure is to be exerted on the inguinal canal, either on one side or simultaneously on both sides. The reflex response is very similar to that of Brudziński's "nape-reflex" (quick flexion of hip and knee). Peiper (1941) described the reflex as a sign of meningitis, which we, too, can confirm. Since, however, the stimulus elicits in his case not extension but flexion, and the reflex is not physiological but one appearing exclusively in pathological conditions, it has, obviously, nothing in common with the crossed inguinal extension reflex.

In most cases the full extension of the leg at the hip and the knee was not accompanied by a plantar flexion of the foot and the toes, corresponding to the extension reflex, but by a dorsal flexion of both, mainly of the big toe, corresponding to the flexion reflex (Figs. 1 and 2). In the electromyographic curve this was shown by the simultaneous contraction of both extensors and flexors (Figs. 3-7). The same can be observed with the electromyographic curve of the flexion reflex (Fig. 8).

The simultaneous contraction of antagonistic muscles is a fact long known in cases of motor activity exerted by volitional effort (Beevor, 1904), and also that the physiological supporting reaction is based on a simultaneous contraction of extensors and flexors (Magnus, 1924; Rademaker, 1931).

In general, the function of the agonistic and
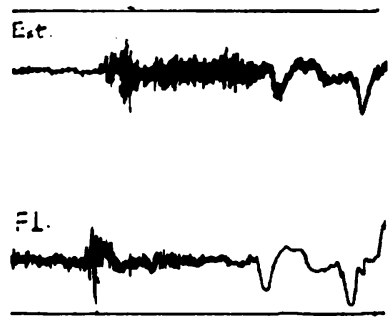

Fig. 8.-Electromyogram of the flexor reflex (normal premature infant). Extensor contractions stronger than flexor.

antagonistic muscles involved in the elicitation of reflexes is controlled by the principle of reciprocal innervation of Sherrington (1910). Nevertheless, the reflex effect may also activate other muscles, notably the antagonists, even under normal conditions (Wachholder and Altenburger, 1924). In their detailed electromyographic studies Foerster and Altenburger (1933a, b, c, d, and 1934) state that the principle of reciprocal innervation does not apply as a rule to the course of the flexion or extension reflexes, because simultaneous contraction of agonists and antagonists can be observed even under normal conditions, but chiefly in cases of pyramidal lesions.

In our cases we are dealing not only with the simultaneous contraction of two antagonistic muscles, but also with the elicitation of two antagonistic reflexes, flexion and extension. Electromyograms show the synchronous contraction of the quadriceps femoris and the gastrocnemius, on the one hand, representing the extension reflex, and that of the hamstring muscles and the tibialis anterior, representing the flexion reflex, on the other. By using an appropriate method the two antagonistic reflexes may be elicited simultaneously even in normal human beings when the cerebral cortex and/ or higher cerebral centres are relatively less developed. This phenomenon can be observed in adults too with pyramidal lesions on eliciting the crossed extension reflex by pinprick (Tóth, 1958). This phenomenon may be designated the "co-reflex phenomenon".

\section{Summary and Conclusions}

The reflexes of medullary automatism have been studied in a series of premature and full-term infants. 
Four methods of eliciting these reflexes have been used. Three of these have been described in the literature, but they are often ineffective in practice.

A fourth method has been added, which has been used experimentally in animals - "the crossed inguinal extension reflex"- and this can be regularly elicited in premature and full-term infants after birth.

The "crossed inguinal extension reflex", a variant of the crossed extension reflex, decreases in intensity in the course of ontogenetical development and, after appearing in rudimentary forms, disappears gradually and/or becomes clinically latent during the first year of life.

Electromyographic studies show that the crossed inguinal extension reflex and the flexion reflex response respectively involve not only the muscles commonly active in them but also the antagonists.

It seems likely that by employing a proper technique both the flexion and the extension reflexes can be elicited at the same time in the early phases of normal nervous development, thus showing a remarkable "co-reflex" phenomenon.

\section{REFERENCES}

André-Thomas, and Saint-Anne Dargassies, S. (1952), Etudes neurologiques sur le nouveau-né et le jeune nourrisson. Masson. Paris.

Beevor, C. E. (1904). The Croonian Lectures on Muscular Movements and Their Representation in the Central Nervous System. Cited by Fulton, J. F. (1949). Adlard, London.

Böhme, A. (1916). Dtsch. Arch. klin. Med., 121, 129.

- (1919). Ergebn. inn. Med. Kinderheilk., 17, 1.

Brown T Graham (1913) Ergebn. Physiol., 13, 279.

- (1916). lbid. 15, 480.

Brudziński, J. (1908). Wien. klin. Wschr., 21, 255.

Foerster, O. (1936). Handbuch der Neurologie., Vol. V, ed. $O$. Bumke, and O. Foerster. Springer, Berlin.

-, and Altenburger, H. (1933a). Z. ges. Neurol. Psychiat., 146, 641.

,--1 (1933b). Ibid., 147, 169.

- - (1933c). Ibid., 147, 779 .

- (1933d). Ibid., 148, 655 .

- - (1934). Ibid., 149, 409.

Fulton, J. F. (1949). Physiology of the Nervous System, 3rd ed. p. 93. Oxford University Press, New York.

Kuhn, R. A. (1950). Brain, 73, 1.

-, and Macht, M. B. (1949). Bull. John Hopk. Hosp., 84, 43.

Magnus, R. (1924). Körperstellung. Springer, Berlin.

Marie, P., and Foix, C. (1912). Rev. neurol. 23, 657

Peiper, A. (1941). Dtsch. med. Wschr., 67, 341

(1956). Die Eigenart der kindlichen Hirntätigkeit. Thieme, Leipzig.

Rademaker, G. G. J. (1931). Das Stehen. Springer, Berlin.

Saint-Anne Dargassies, S. (1955). Ét. néo-natal., 4, 71.

Sherrington, C. S. (1910). J. Physiol (Lond.), 40, 28.

Stengel, R. (1945). Der gleichsinnige gekreuzte Beugereflex der Beine, Diss. Greifswald: Cited by Peiper, A. (1956).

Tóth. Sz. (1958). Unpublished.

Wachholder, K., and Altenburger, H. (1924). Pfüg. Arch. ges. Physiol. 203, 620.

Walshe, F. M. R. (1914). Brain, 37, 269.

Wegener, H. (1927). Mschr. Psychiat. Neurol., 66, 342. 